\title{
WEBVR VS. PICTURES OF PRODUCTS IN E-COMMERCE: EFFECTS ON TRUST, PERCEIVED EASE OF USE, PERCEIVED USEFULNESS, AND INTENTION TO USE
}

\author{
Roger Seiler ${ }^{1}$ and Thomas Keller ${ }^{2}$ \\ ${ }^{1}$ Zurich University of Applied Science, St.-Georgen-Platz 2, CH-8400 Winterthur, Switzerland \\ ${ }^{2}$ Zurich University of Applied Science, Theaterstrasse 17, CH-8400 Winterthur, Switzerland
}

\begin{abstract}
Technologies around augmented and virtual reality are advancing, and adoption is gaining momentum because of falling hardware costs. This paper provides insights into the use of online interactive 3D product representations as opposed to static pictures. An online experiment is conducted to examine effects on trust, intention to use, perceived usefulness, and perceived ease of use. A treatment group is exposed to a 3D interactive representation whereas the control group is presented with static pictures. The findings of this research observe higher levels of trust, perceived usefulness, perceived ease of use, and intention to use. These aspects tend to positively affect desired consumer behavior and are thus relevant for e-shopping vendors. The use of interactive 3D representation in e-commerce is beneficial, and thus, e-commerce vendors seeking to build trust and profit from the positive effect this may have on purchase intention are advised to use interactive 3D product representations online and strongly consider WebVR technology to implement such representations.
\end{abstract}

\section{KEYWORDS}

Virtual Reality, WebVR, Trust, e-Commerce, Experiment, TAM

\section{INTRODUCTION}

Previous work has been conducted on getting Web developers to use augmented reality (AR) and virtual reality (VR) technology (Dibbern et al., 2018) as well as combining WebVR with WebRTC for 360-degree social VR experiences (Gunkel et al., 2017). Furthermore, using WebVR frameworks such as A-Frame to develop a TV platform has been investigated as well (Hedelin, 2017). As AR and VR technologies are promising in various fields, their adoption to the field of e-commerce seems valid. Success factors have been found regarding the application of VR to e-commerce and trust-building within this context (e.g., Papadopoulou (2007). More specific research has been conducted regarding AR and VR in luxury goods (Harren et al., 2019). Sales of sunglasses and watches online can be positively affected by AR (Yim et al., 2017), and immersion seems to mediate interactivity/vividness and usefulness and enjoyment when comparing AR and Web conditions (Yim et al., 2017).

Recent research refers to a comparison of an AR app and WebVR whereas this paper sheds light on the technology itself by comparing interactive 3D and 2D representations of products in e-commerce to gain further insights into how this technology affects consumer-related aspects such as trust, perceived use, perceived usefulness, and intention to use.

Subsequently, the research objectives, relevance, and contribution of the paper are outlined before moving on to the state of the art.

This work addresses two research questions. The first addresses the technology and how VR affects trust in an e-commerce context. The second concerns the technology acceptance model (TAM) and whether it holds true in the context of VR use in e-commerce.

RQ1: How does VR technology affect trust in e-commerce?

RQ2: Does the TAM hold true in the context of e-commerce? 
Evidence from the field of education shows promising effects of AR as well as VR on students' learning behavior (Liu et al., 2017) and can even be used when teaching languages (Hao, 2019). Meta-analyses further support these findings (Garzón et al., 2019). Empirical evidence shows the cost-saving potential of these virtual technologies (Eller, 2017). However, these positive aspects of AR and VR are not without disadvantages. Technical complexity and cybersickness too are especially mentioned (Batdi and Talan, 2019).

The fields of VR technology application are many and broad, thus making them potentially relevant. They span from spatial planning such as the preservation of historical monuments to marketing applications in tourism, where the multisensory response of tourists is used (Aichner et al., 2019, p. 13 ff.). Furthermore, market growth numbers as well as growth predictions are promising. Price Waterhouse Cooper (PWC) identifies a new mass market (Ballhaus and Ketterer, 2017) while IDC mentions a 76.9\% yearly growth Compound annual growth rate (CAGR) and a \$13.6 billion market size (Carosella, 2020). Current spending on AR and VR technologies is largest in China ( $\$ 5.8$ billion), the United States ( $\$ 5.1$ billion), and Western Europe (\$3.3 billion) whereas Western Europe is expected to be in second place in 2023 (Shirer and Torchia, 2019). For the D-A-CH (Germany (D), Austria (A), and Switzerland (CH)) region, the technology also seems promising and is expanding from science to business. An IDG Communications Media study reveals that $40.3 \%$ of $200 \mathrm{C}$-level executives are using either AR or VR in their companies, $32.8 \%$ are planning to do so in the next 12 months, and only $26.9 \%$ have no future plans or projects associated with AR or VR (Hülsbömer and Kersten, 2019). This is in line with Gartner, who identifies VR and AR as one of the top 10 technology trends (Gartner, 2017).

In 2018, hardware costs were among the identified reasons for not buying VR hardware (Esser, 2018). The cost of hardware is decreasing, and thus, AR and VR are becoming more affordable (Economist, 2020). Therefore, AR and VR are worth looking into because of their relevance for industry and science and their likely expansion.

This paper seeks to shed light on the use of interactive 3D representations in e-commerce compared to static pictures of products. This paper also intends to verify if the TAM proposed by Davis (1989) holds true in this context as well. Furthermore, this paper contributes to knowledge by providing insights relevant to e-commerce vendors selling products online, as the findings provide guidance to online product presentation. A special thank you to Oliver Moser of the ZHAW for his support.

\section{STATE OF THE ART}

In this section, an overview of relevant literature and terms, such as augmented, virtual, mixed, and extended reality is provided before moving on to customer-related constructs such as trust, intention to use, perceived usefulness, and ease of use.

AR enriches the perception of the real world by overlaying it, for example, with information or data such as the current temperature. A heads-up display in a car is an example of augmented reality. VR is a multisensory construction or reconstruction of a virtual world that replaces one's perception of the real world (Dörner et al., 2019). The reality virtuality (RV) continuum (Milgram et al., 1994) helps categorize applications in terms of the amount of information they add to overlay the real world. Depending on this amount of information, an application has more augmented or shifts toward having a more virtual character (Milgram et al., 1994). This scope between a minimally augmented and a highly augmented world is called mixed reality (Milgram et al., 1994). In recent years, the term extended reality (XR) has been introduced, covering mixed reality (MR), AR and VR (Çöltekin et al., 2020). Furthermore, technologies have been introduced to construct virtual worlds in the World Wide Web called WebVR. This technology seems promising and may further foster the adoption of VR (Dibbern et al., 2018). This approach to constructing virtual worlds is interesting, as compared with both $\mathrm{AR}$ and VR, which require technical devices or head-mounted displays (HMDs), WebVR can be run using most common browsers. Three-hundred-sixty-degree VR videos supported by most browsers allow users to interact with the video and look around in its virtual world. Meanwhile, WebVR may only require a browser that can run on a desktop, laptop, or smartphone to enter virtual worlds for stereoscopic and more immersive experiences requiring additional hardware. An affordable device is Google Cardboard, which works for most devices and is literally made of cardboard, hence the name. The application must be put into VR mode. This splits the 
screen into two: the left part for the left eye and the right part for the right eye display content in slightly different perspectives. This enables depth perception and hence leads to a more immersive experience. HMDs such as the HTC Vive Pro, the HTC Cosmos, or Oculus Rift are more expensive. Therefore, in an e-commerce setting, the inexpensive and lightweight Cardboard could be sent to customers as a marketing giveaway to enable stereoscopic immersive experiences at home as well as WebVR applications that are more practical and thus more prone to be used in the electronic vending setting than high-end HMD hardware that may be used in showrooms or retail stores to provide an interactive and immersive experience.

Not only do AR and VR show beneficial effects on learning performance (see section 0), but trust can also be positively influenced. Positive effects of this technology (e.g., on learning and consumers' product information acquisition) have been mentioned in the introduction (see section 1). Furthermore, preliminary research has been conducted in the context of e-commerce. Additionally, fostering acceptance using AR (Wintersberger et al., 2019) or exploring TAM in the context of AR (López et al., 2019) have been explored.

However, to the knowledge of the authors, little research has been conducted comparing traditional 2D product pictures and VR approaches. Early approaches report positive effects on social aspects and on trust-building (Papadopoulou, 2007). These results are confirmed by later research stating that trust or disgust is also fostered in the virtual world by mere exposure to videos (Kugler et al., 2019). Perceived presence builds trust online (Salanitri et al., 2016). Furthermore, TAM and trust seem related (Salantri, 2018). Nevertheless, little research is found on VR and its effect on trust (Yung and Khoo-Lattimore, 2019). Some studies on agents (Demeure et al., 2011) and on expertise comparing avatar-, video-, and robot-mediated interaction on trust (Pan and Steed, 2016) can be seen as rare exceptions. Research is also scarce on social presence (Salanitri et al., 2016) and its effects on VR and trust. Therefore, the authors focus on VR technology itself and its possible impact on trust. Other models such as the lazy user model (LUM) and TAM variants 2 to 3 as well as Unified Theory of Acceptance and Use of Technology (UTAUT) are not considered in this preliminary research to avoid overcomplication and for comparability reasons with existing research such as those on VR (Sagnier et al., 2020) or AR (López et al., 2019) or older research that also build on TAM (Gefen et al., 2003; Hampton-Sosa and Koufaris, 2005).

The following four hypotheses (see Table 1) are based on the abovementioned state of the art. Hypothesis 1 is derived, as past research shows that 3D can have positive effects on trust (e.g., Nassiri (2008). If TAM holds true in this context, based on prior research such as Davis (1989), hypotheses 2, 3, and 4 are derived and modified according to the $3 \mathrm{D}$ online context.

Table 1. Overview of hypotheses

\begin{tabular}{clc}
\hline$\#$ & Hypotheses & $\begin{array}{c}\text { Result } \\
\text { (see section 4) }\end{array}$ \\
1 & 3D has a positive effect on trust. & Accept \\
2 & 3D has a positive effect on perceived usefulness. & Accept \\
3 & 3D has a positive effect on perceived ease of use. & Accept \\
4 & 3D representation has a positive effect on intention to use. & Accept \\
\hline
\end{tabular}

\section{MATERIALS AND METHOD}

An online experiment was used as the method in this paper, which compares 2D (control) and 3D WebVR (treatment) representations of a chair (Figure 1). The chair was chosen since it may be a product bought online, as the pandemic calls for more home offices, and people may buy new chairs that are more suitable for longer working hours at home. This product was also used in a recent study by Kowalczuk et al. (2020). Furthermore, participants were presented with a short introduction scenario and were instructed to evaluate the chair, as this would be the case in a typical purchasing setting. The chair was presented in 3D WebVR, allowing participants to rotate and interact with the chair in the treatment group. The $2 \mathrm{D}$ representation pictures showed the chair from each side but with no interaction or option to rotate it. A number in red was added to the 3D model to check whether all participants saw the back of the chair, indicating that interaction in the form of chair rotation was done. The same number was used in the control group to have identical representations of the chairs and a control variable to verify that participants swiveled the chair around and thus interacted with it in the $3 \mathrm{D}$ setting. 
An online questionnaire (via LimeSurvey) was created using scales from previous research allowing for comparability of the four main constructs: trust, perceived ease of use, perceived usefulness, and intention to use. Furthermore, control variables (age, gender, education, and experience with 2D and 3D online) were measured and controlled for confounding effects on the main four constructs. Experience was further subdivided into that with $2 \mathrm{D}$ and $3 \mathrm{D}$ video online, WebVR, gaming experience, as well as smartphone use. To conduct the experiment, users were given the task of shopping online for an office chair prior to the 2D (control) or 3D (treatment) presentations of the product and before questions were administered on the main constructs (trust, perceived ease of use, perceived usefulness, and intention to use) as well as sociodemographic variables. A link was sent to participants via e-mail using a student sample from the Greater Zurich Area as well as through snowball sampling. A total of 122 submitted questionnaires were retrieved, and data analysis was conducted using IBM SPSS Statistics 27 . The average age was 31.32 years, and $54.3 \%$ of the participants were female and $39.4 \%$ were male while $6.3 \%$ did not reveal their gender.

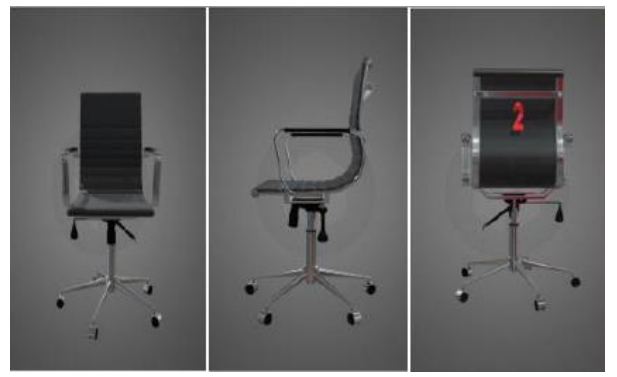

Figure 1. Visual of the office chair used

\section{RESULTS, DISCUSSION, LIMITATIONS AND FURTHER RESEARCH}

A t-test for control variable effects showed that none of the control variables - age, gender, education, and experience (WebVR, AR, VR, or smartphone use)—were significant. Before conducting further analysis, reliability analysis and factor analysis were conducted.

All Cronbach's alpha values for trust (.884, seven items), perceived ease of use (.856, five items), perceived usefulness (.928, six items), and intention to use (.954, six items) were well above the cutoff value of .7 (Nunally, 1978), and therefore, the constructs were analyzed further.

The measure of sampling adequacy (MSA) Kaiser-Meyer-Olkin (KMO) test (.894) was well above .5, and the Barlett test value was significant $\left(\chi^{2}(276)=2055, \mathrm{p}<.000\right)$. Therefore, further data analysis via factor analysis was conducted.

The factor analysis (main component analysis with varimax rotation and Kaiser normalization) showed no relevant cross loadings (see Table 2), and therefore, further testing was done using these constructs.

Descriptive analysis, as the starting point of the group comparison, shows that in the 3D representation, higher mean values of all constructs can be reported (see Table 3) although slightly higher standard deviations were observed. Therefore, a t-test group comparison was conducted (see Table 4).

All constructs showed significantly higher values for the treatment group than for the control group. Perceived ease of use showed the highest significance followed by intention to use. Trust and perceived usefulness, both with the same and significant values, are slightly lower than the other constructs. Therefore, all hypotheses were accepted (see Table 3).

The results indicated that trust can be built by showing interactive $3 \mathrm{D}$ representations online using $360^{\circ}$ videos of products. These findings are in line with prior research such as Papadopoulou (2007) or, more recently, Salantri (2018). This is relevant to e-commerce vendors, as research showed positive effects of trust on purchase intentions (D’Alessandro et al., 2012; Lu et al., 2016). Therefore, e-commerce websites seeking to build online trust are advised to whether they can implement such technology in their Web shops.

Furthermore, positive effects can be reported regarding both perceived usefulness and ease of use relevant to e-shop vendors. This further adds to the implication of conducting pilot projects or A/B testing to evaluate whether the specific target group and customers of a specific Web shop prefer product representations as shown in this paper over traditional ones. Past research indicates that higher levels of perceived usefulness can positively influence purchase intentions (Moslehpour et al., 2018), and this also adds to the implication of testing the product presentation approach in this paper. 
Table 2. Factor analysis results

\begin{tabular}{|l|c|c|c|c|}
\hline & $\mathbf{1}$ & $\mathbf{2}$ & $\mathbf{3}$ & $\mathbf{4}$ \\
\hline TRUST1 & & & .611 & \\
\hline TRUST2 & & & .574 & \\
\hline TRUST3 & & & .782 & \\
\hline TRUST4 & & & .637 & \\
\hline TRUST5 & & & .694 & \\
\hline TRUST6 & & & .822 & \\
\hline TRUST7 & & & .856 & \\
\hline PU1 & & .799 & & \\
\hline PU2 & & .773 & & \\
\hline PU3 & & .804 & & \\
\hline PU4 & & .853 & & \\
\hline PU5 & & .852 & & .748 \\
\hline PU6 & & .552 & & \\
\hline PEOU1 & & & & \\
\hline PEOU2 & & & & \\
\hline PEOU3 & & & & \\
\hline PEOU4 & & & & \\
\hline PEOU5 & & & & \\
\hline ITU1 & .813 & & & \\
\hline ITU2 & .852 & & & \\
\hline ITU3 & .878 & & & \\
\hline ITU4 & .821 & & & \\
\hline ITU5 & .781 & & & \\
\hline ITU6 & .778 & & & \\
\hline
\end{tabular}

Table 3. Group comparison

\begin{tabular}{|c|c|c|c|c|c|}
\hline & Group & $\mathbf{n}$ & mean & S.D. & S.E. \\
\hline \multirow{2}{*}{ Trust } & 3D & 68 & 5.885 & .918 & .111 \\
\cline { 2 - 6 } & 2D & 50 & 5.537 & .717 & .101 \\
\hline \multirow{2}{*}{ PU } & 3D & 71 & 4.960 & 1.378 & .164 \\
\cline { 2 - 6 } & 2D & 51 & 4.425 & 1.206 & .169 \\
\hline \multirow{2}{*}{ PEOU } & 3D & 70 & 5.537 & 1.103 & .132 \\
\cline { 2 - 6 } & 2D & 43 & 4.986 & .954 & .145 \\
\hline \multirow{2}{*}{ ITU } & 3D & 66 & 5.172 & 1.323 & .162 \\
\cline { 2 - 6 } & 2D & 51 & 4.611 & 1.350 & .189 \\
\hline
\end{tabular}


Table 4. T-test results

\begin{tabular}{|l|c|c|c|}
\hline & T & df & p-value (two-tailed) \\
\hline Trust & 2.222 & 116 & .028 \\
\hline PU & 2.228 & 120 & .028 \\
\hline PEOU & 2.712 & 111 & .008 \\
\hline ITU & 2.253 & 115 & .026 \\
\hline
\end{tabular}

Since this research was an initial approach to gaining insights into how mere VR representation may affect TAM in an e-commerce context, a student sample was used. A young target group should not be an issue in e-commerce, but results may vary depending on a specific target group.

Furthermore, the study examined intentions to use a system and not buying behavior or other relevant e-commerce variables such as satisfaction or customer value. An additional limitation was the product type, which is an office chair; results may vary for other goods. A further limitation was that these results may not hold true if users shopped on their mobile devices.

Further research may look deeper into the effects of VR technology in this context by adding other variables such as customer satisfaction, actual purchasing behavior, or customer value. This paper used a video representation, and further research may want to follow up by creating product configurators or interactive $3 \mathrm{D}$ product representations to check whether results vary in this context.

\section{CONCLUSION}

The use of interactive 3D product representations online (e.g. WebVR) compared to pictures showed positive effects on e-commerce-relevant variables such as trust, intention to use, perceived usefulness, and perceived ease of use. These results may vary depending on the product type or goods presented online, but based on prior research as well as customer perception literature, an interactive online 3D experience such as the one provided by WebVR tends to positively influence information acquisition and memory, which in turn is relevant to the online selling of products.

\section{REFERENCES}

Aichner, T., Maurer, O., Nippa, M., Tonezzani, S., 2019. Zur Relevanz von Virtual Reality in Wissenschaft und Praxis, in: Virtual Reality Im Tourismus, Essentials. Springer Fachmedien Wiesbaden, Wiesbaden, pp. 5-15. https://doi.org/10.1007/978-3-658-23865-0_2

Ballhaus, W., Ketterer, S., 2017. Studie: Deutscher Virtual-Reality-Markt wächst über die Nische hinaus [WWW Document]. PwC. URL https://www.pwc.de/de/technologie-medien-und-telekommunikation/studie-deutscher-virtualreality-markt-waechst-ueber-die-nische-hinaus.html (accessed 11.30.20).

Batdi, V., Talan, T., 2019. Augmented reality applications: A Meta-analysis and thematic analysis. Turkish Journal of Education 8, 276-297. https://doi.org/10.19128/turje.581424

Carosella, G., 2020. Pandemic Tempers Growth in AR/VR Spending, but the Long-Term Outlook is Positive, says IDC [WWW Document]. IDC: The premier global market intelligence company. URL https://www.idc.com/getdoc.jsp?containerId=prEUR146720420 (accessed 10.22.20).

Çöltekin, A., Griffin, A.L., Slingsby, A., Robinson, A.C., Christophe, S., Rautenbach, V., Chen, M., Pettit, C., Klippel, A., 2020. Geospatial Information Visualization and Extended Reality Displays, in: Guo, H., Goodchild, M.F., Annoni, A. (Eds.), Manual of Digital Earth. Springer, Singapore, pp. 229-277. https://doi.org/10.1007/978-981-329915-3 7

D’Alessandro, S., Girardi, A., Tiangsoongnern, L., 2012. Perceived risk and trust as antecedents of online purchasing behavior in the USA gemstone industry. Asia Pac Jnl of Mrkting \& Log 24, 433-460. https://doi.org/10.1108/13555851211237902

Davis, F.D., 1989. Perceived Usefulness, Perceived Ease of Use, and User Acceptance of Information Technology. MIS Quarterly 13, 318-340. 
Demeure, V., Niewiadomski, R., Pelachaud, C., 2011. How Is Believability of a Virtual Agent Related to Warmth, Competence, Personification, and Embodiment? Presence: Teleoperators and Virtual Environments 20, 431-448. https://doi.org/10.1162/PRES_a_00065

Dibbern, C., Uhr, M., Krupke, D., Steinicke, F., 2018. Can WebVR further the adoption of Virtual Reality?, in: Hess, S., Fischer, H. (Eds.), Mensch Und Computer 2018 - Usability Professionals. Gesellschaft für Informatik e.V. Und German UPA e.V., Bonn, pp. 377-384.

Dörner, R., Broll, W., Grimm, P., Jung, B. (Eds.), 2019. Virtual und Augmented Reality (VR/AR): Grundlagen und Methoden der Virtuellen und Augmentierten Realität. Springer Berlin Heidelberg, Berlin, Heidelberg. https://doi.org/10.1007/978-3-662-58861-1

Economist, 2020. Headset technology is cheaper and better than ever. The Economist Technology QUARTERLY.

Eller, C.H., 2017. Relevanz und Eignung der Virtaul und Augmented Reality- Technologie für Hochschulen (Bachelorarbeit). ZHAW SML Studiengang Bachelor Wirtschaftsinformatik, Winterthur.

Esser, R., 2018. The Reality about Virtual and Augmented Reality- An Immersive Customer Perspective.

Gartner, 2017. Top Trends in the Gartner Hype Cycle for Emerging Technologies, 2017 [WWW Document]. Smarter With Gartner. URL https://www.gartner.com/smarterwithgartner/top-trends-in-the-gartner-hype-cycle-for-emergingtechnologies-2017/ (accessed 8.24.18)

Garzón, J., Pavón, J., Baldiris, S., 2019. Systematic review and meta-analysis of augmented reality in educational settings. Virtual Reality 23, 447-459. https://doi.org/10.1007/s10055-019-00379-9

Gefen, D., Karahanna, E., Straub, D.W., 2003. Trust and TAM in Online Shopping: An Integrated Model. MIS Quarterly 27, 51-90. https://doi.org/10.2307/30036519

Gunkel, S., Prins, M., Stokking, H., Niamut, O., 2017. WebVR meets WebRTC: Towards 360-degree social VR experiences, in: 2017 IEEE Virtual Reality (VR). Presented at the 2017 IEEE Virtual Reality (VR), IEEE, Los Angeles, CA, USA, pp. 457-458. https://doi.org/10.1109/VR.2017.7892377

Hampton-Sosa, W., Koufaris, M., 2005. The Effect of Web Site Perceptions on Initial Trust in the Owner Company. International Journal of Electronic Commerce 10, 55-81. https://doi.org/10.1080/10864415.2005.11043965

Hao, K., 2019. A new immersive classroom uses AI and VR to teach Mandarin Chinese [WWW Document]. MIT Technology Review. URL https://www.technologyreview.com/s/613963/ai-vr-education-immersive-classroomchinese-ibm/ (accessed 3.29.20).

Harren, B., Seiler, R., Müller, S., 2019. Augmented Reality und Virtual Reality im Premium- und Luxus-Retail, in: Uhl, A., Loretan, S. (Eds.), Digitalisierung in der Praxis. Springer Fachmedien Wiesbaden, Wiesbaden, pp. 183-195. https://doi.org/10.1007/978-3-658-26137-5_12

Hedelin, H., 2017. Design and evaluation of a user interface for a WebVR TV platform developed with A-Frame.

Hülsbömer, S., Kersten, P., 2019. Studie Virtual Reality / Augmented Reality 2019. IDG Business Media GmbH, München.

Kowalczuk, P., Siepmann (née Scheiben), C., Adler, J., 2020. Cognitive, affective, and behavioral consumer responses to augmented reality in e-commerce: A comparative study. Journal of Business Research. https://doi.org/10.1016/j.jbusres.2020.10.050

Kugler, T., Ye, B., Motro, D., Noussair, C.N., 2019. On Trust and Disgust: Evidence From Face Reading and Virtual Reality. Social Psychological and Personality 194855061985630. https://doi.org/10.1177/1948550619856302

Liu, D., Bhagat, K.K., Gao, Y., Chang, T.-W., Huang, R., 2017. The Potentials and Trends of Virtual Reality in Education, in: Liu, D., Dede, C., Huang, R., Richards, J. (Eds.), Virtual, Augmented, and Mixed Realities in Education. Springer Singapore, Singapore, pp. 105-130. https://doi.org/10.1007/978-981-10-5490-7_7

López, W.L.G., Cuji, B.R., Abásolo, M.J., Sailema, G.L.A., 2019. Technological Acceptance Model (TAM) using Augmented Reality in University Learning Scenarios, in: 2019 14th Iberian Conference on Information Systems and Technologies (CISTI). Presented at the 2019 14th Iberian Conference on Information Systems and Technologies (CISTI), pp. 1-6. https://doi.org/10.23919/CISTI.2019.8760784

Lu, B., Fan, W., Zhou, M., 2016. Social presence, trust, and social commerce purchase intention: An empirical research. Computers in Human Behavior 56, 225-237. https://doi.org/10.1016/j.chb.2015.11.057

Milgram, P., Takemura, H., Utsumi, a, Kishino, F., 1994. Mixed Reality ( MR ) Reality-Virtuality ( RV ) Continuum. Systems Research 2351, 282-292. https://doi.org/10.1.1.83.6861

Moslehpour, M., Pham, V.K., Wong, W.-K., Bilgiçli, İ., 2018. e-Purchase Intention of Taiwanese Consumers: Sustainable Mediation of Perceived Usefulness and Perceived Ease of Use. Sustainability 10, 234. https://doi.org/10.3390/su10010234 
Nassiri, N., 2008. Increasing trust through the use of 3d e-commerce environment, in: Proceedings of the 2008 ACM Symposium on Applied Computing, SAC '08. Association for Computing Machinery, New York, NY, USA, pp. 1463-1466. https://doi.org/10.1145/1363686.1364028

Nunally, J., 1978. Psychometric theory. McGraw-Hill, New York.

Pan, Y., Steed, A., 2016. A Comparison of Avatar-, Video-, and Robot-Mediated Interaction on Users' Trust in Expertise. Front. Robot. AI 3. https://doi.org/10.3389/frobt.2016.00012

Papadopoulou, P., 2007. Applying virtual reality for trust-building e-commerce environments. Virtual Reality 11, 107-127. https://doi.org/10.1007/s10055-006-0059-x

Sagnier, C., Loup-Escande, E., Lourdeaux, D., Thouvenin, I., Valléry, G., 2020. User Acceptance of Virtual Reality: An Extended Technology Acceptance Model. International Journal of Human-Computer Interaction 1, 1-15. https://doi.org/10.1080/10447318.2019.1708612

Salanitri, D., Lawson, G., Waterfield, B., 2016. The Relationship Between Presence and Trust in Virtual Reality, in: Proceedings of the European Conference on Cognitive Ergonomics - ECCE '16. Presented at the the European Conference, ACM Press, Nottingham, United Kingdom, pp. 1-4. https://doi.org/10.1145/2970930.2970947

Salantri, D., 2018. Trust in Virtual Reality. University of Nottingham, Nottingham UK.

Shirer, M., Torchia, M., 2019. Worldwide Spending on Augmented and Virtual Reality Expected to Reach \$18.8 Billion in 2020, According to IDC [WWW Document]. IDC: The premier global market intelligence company. URL https://www.idc.com/getdoc.jsp?containerId=prUS45679219 (accessed 10.22.20).

Wintersberger, P., Frison, A.-K., Riener, A., Sawitzky, T. von, 2019. Fostering User Acceptance and Trust in Fully Automated Vehicles: Evaluating the Potential of Augmented Reality. PRESENCE: Virtual and Augmented Reality 27, 46-62. https://doi.org/10.1162/pres_a_00320

Yim, M.Y.-C., Chu, S.-C., Sauer, P.L., 2017. Is Augmented Reality Technology an Effective Tool for E-commerce? An Interactivity and Vividness Perspective. Journal of Interactive Marketing 39, 89-103. https://doi.org/10.1016/j.intmar.2017.04.001

Yung, R., Khoo-Lattimore, C., 2019. New realities: a systematic literature review on virtual reality and augmented reality in tourism research. Current Issues in Tourism 22, 2056-2081. https://doi.org/10.1080/13683500.2017.1417359 